RICYDE. Revista Internacional de Ciencias del Deporte doi: $10.5232 /$ ricyde

Rev. int. cienc. deporte

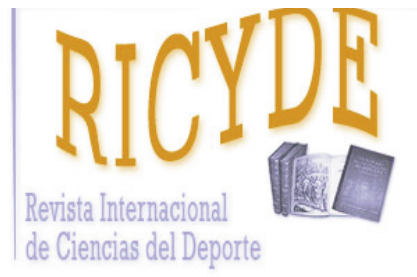

RICYDE. Revista Internacional de Ciencias del Deporte VOLUME XIV - YEAR XIV

Pages:29-41 ISSN:1885-3137

Issue: 51 - January - 2018

\title{
Effect of gender and match outcome on professional padel competition Efecto del género y del resultado final del partido en competiciones profesionales de pádel
}

\author{
Corrado Lupo ${ }^{1}$, Giancarlo Condello², Javier Courel-Ibáñez ${ }^{3}$, Chiara Gallo4, \\ Daniele Conte2 ${ }^{2}$ Antonio Tessitore ${ }^{2}$
}

1.NeuroMuscularFunction Research Group, School of Exercise and Sport Sciences (SUISM), Department of Medical Sciences, University of Torino, Turin, Italy.

2.Department of Movement, Human and Health Sciences, University of Rome "Foro Italico", Rome, Italy.

3.Department of Physical Education and Sport, Faculty of Sport Sciences, University of Granada, Spain.

4.School of Exercise \& Sport Sciences (SUISM), University of Torino, Turin, Italy.

\begin{abstract}
The present study aimed at analyzing the technical and tactical aspects of professional padel matches in relation to gender and match outcome. For this purpose, a notational analysis was performed on 22 official matches of the World Padel Tour 2016 by means of 18 technical and tactical indicators. A non-parametric approach was applied to evaluate differences $(P \leq 0.05)$ between gender and match outcome subgroups. For gender, differences emerged for the occurrence $(P<0.001)$ and duration $(P<0.001)$ of rallies, backhand strokes $(P=0.02)$ and backhand volley $(P=0.027)$, strokes close to net $(P=0.001)$ and from midfield zone $(P=0.012)$, smashes determining ball out $(P<0.001)$, and first service faults $(P<0.001)$. For match outcome, a difference was found only for the occurrence of winning rallies (in general: $\mathrm{P}<0.001$; in female performance: $\mathrm{P}=0.009$; in male performance: $P=0.001$ ). Although findings highlight that padel performance can be discriminated only for gender, whereas winning and losing performances resulted similar, probably for the influence of different playing styles, this study could represent a valuable reference for further analyses and more effective padel training plans.
\end{abstract}

Key Words: racket sports; notational analysis; technical indicators; tactical indicators; net games; padel players.

\section{Resumen}

El presente estudio tuvo como objetivo analizar aspectos técnicos y tácticos en pádel profesional en relación con el género y el resultado final del partido. Para ello, se realizó un análisis notacional de 22 partidos oficiales del circuito profesional World Padel Tour 2016 registrando 18 indicadores técnicos y tácticos. Se llevó a cabo un análisis no paramétrico de los datos para comparar las diferencias $(P \leq 0.05)$ entre los subgrupos de género y resultado final. Para el género, se encontraron diferencias en el número $(P<0.001)$ y duración $(P<0.001)$ de los rallies, golpes de revés $(P=0.02)$ y voleas de revés $(P=0.027)$, golpes cerca de la red $(P<0.001)$ y golpes desde la zona intermedia del campo $(P=0.012)$, remates ganadores por bola fuera del campo $(P<0.001)$ y faltas de primer saque $(P<0.001)$. Para el resultado del partido, se encontraron diferencias únicamente en el número de rallies ganadores (en general: $P<0.001$; en mujeres: $P=0.009$; en hombres: $P=0.001$ ). Los resultados obtenidos ponen de manifiesto importantes diferencias en el rendimiento de pádel en cuanto al género, observando resultados similares entre ganadores y perdedores probablemente como consecuencia de diferentes estilos de juego. Este estudio por tanto puede servir como referencia válida para el desarrollo tanto de futuros análisis como de planes de entrenamiento más efectivos en pádel.

Palabras clave: indicadores técnicos; indicadores tácticos; frecuencia cardiac; contramovimiento; prensión manual. 
Lupo, C.; Condello, G.; Courel-Ibañez, J.; Gallo, C.; Conte, D., \& Tessitore, A. (2018). Effect of gender and match outcome on professional padel competition. RICYDE. Revista internacional de ciencias del deporte, 51(14), 29-41. https://doi.org/10.5232/ricyde2018.05103

\section{Introduction}

I nvented in Acapulco (Mexico) in 1969, padel is a racket sport that after being very popular in South America and Spain is now beginning to spread rapidly across Europe and other continents. Its number of practitioners enhanced both at amateur and competitive levels, and probably determined the substantial decrease of tennis practitioners in countries such as Spain (Courel-Ibáñez, Sánchez-Alcaraz, Benítez, \& Echegaray, 2017).

Similar to tennis and squash, padel can be considered a net ball and racquet game. The similarities with tennis refer to the rules and the scoring system, even though some adaptations have been adopted, such as the underhand serve. However, professional padel is usually a pair game and is played in an enclosed synthetic glass and metal court allowing the ball to bounce on lateral and back walls for rallies. The court measures $10 \mathrm{~m}$ (wide) and $20 \mathrm{~m}$ (length), and it is divided by a normal tennis net $(0.88 \mathrm{~m}$ at the center strap and $0.92 \mathrm{~m}$ at the post) in the middle. The back wall is three $\mathrm{m}$ high and the side walls are three $\mathrm{m}$ high and two $\mathrm{m}$ long ending on another wall two $\mathrm{m}$ high and two $\mathrm{m}$ long. The rest of the court, for each half and later side, consisted of two metallic panels of equal dimension $(2.59 \mathrm{~m}$ long and three $\mathrm{m}$ high) and one gate $(0.82 \mathrm{~m}$ long and two $\mathrm{m}$ high). Each half court is composed by two service boxes, which are defined by the service line, which is parallel, and $6.95 \mathrm{~m}$ distant with respect to net and a perpendicular line dividing the service and net lines.

Despite the growing popularity of this sport and according to previous studies (Lees, 2003; Akpinar, Devrilmez, \& Kirazci, 2012) which assumed that the major racket sports are badminton, squash, table tennis and tennis, no consideration has been provided for padel. As consequence, research in padel practitioners is rather poor with respect to that of other similar racket sports such as tennis (Ferrauti, Bergeron, Pluim, \& Weber, 2001; O'Donoghue \& Ingram, 2001; Smekal et al., 2001), badminton (Cabello \& González-Badillo, 2003; Faude et al., 2007, Ooi et al., 2009), and squash (Chin, Steininger, So, Clark, \& Wong, 1995; Girard et al., 2007). More recent research have remarked this need (Villena-Serrano, Castro-López, Lara-Sánchez, \& Cachón-Zagalaz, 2016) observing a lack of padel investigations in the available research.

Nevertheless, in a study on youth top level padel practitioners, mean time of rallies was approximately seven s and mean time of rest between rallies at nine s, with a time of pausereal time ratio of 1:0.79 s (Carrasco, Romero, Sanudo, \& de Hoyo, 2011). Conversely, in another study focused on the temporal structure and characteristic game actions of Spanish regional padel competition level, the mean time of rallies was nine s (Sánchez-Alcaraz Martinez, 2014a). In addition, in the latter study, the average number of strokes per rally was around seven (with eight as standard deviation), and a similar number of strokes originated from the right and left court side strokes.

Previous researches in sports performance analysis have shown different responses in men and women athletes during the competition (Fernandez-Fernandez, de la Aleja Tellez, MoyaRamón, Cabello-Manrique, \& Mendez-Villanueva, 2013; Torres-Luque, Ramirez, CabelliManrique, Nikolaidis, \& Alvero-Cruz, 2015). In padel, Sánchez Alcaraz (2014b) explored the time structure and game action aspects of the first sets of ten men and women final matches of the Padel Pro Tour, reporting gender differences for the average set duration (men: $35.1 \pm$ $12 \mathrm{~min}$, women: $36.3 \pm 7.9 \mathrm{~min}$ ), the live time of set (men: $11.2 \pm 3.6 \mathrm{~min}$, women: $14.1 \pm$ $3.3 \mathrm{~min}$ ), and the average rally duration (men: $11.6 \pm 10.6 \mathrm{~s}$, women: $18.7 \pm 13.4 \mathrm{~s}$ ). Differently, the rest time between rallies (men: $24.7 \pm 25.3 \mathrm{~s}$, women: $21.4 \pm 18.9 \mathrm{~s}$ ) and the average numbers of strokes per rally (men: $9.4 \pm 9.5$, women: $9.1 \pm 5.4$ ) were quite the same. 
Lupo, C.; Condello, G.; Courel-Ibañez, J.; Gallo, C.; Conte, D., \& Tessitore, A. (2018). Effect of gender and match outcome on professional padel competition. RICYDE. Revista internacional de ciencias del deporte, 51(14), 29-41. https://doi.org/10.5232/ricyde2018.05103

Furthermore, in another study on professional padel players (Torres-Luque, Ramirez, Cabello-Manrique, Nikolaidis, \& Alvero-Cruz, 2015), women reported higher values in real time, rest time, and number of strokes than men, and a different frequency of occurrence related to the percentage of type of strokes (backhand volley, indirect forehand lob, backhand lob) emerged. Hence, the match activity profiles of padel appear to be different in men and women performances. This fact is important because coaches should design their drills and conditioning programs to ensure that training aims and contents are properly tailored to the competition demands (García-Benítez, Courel-Ibáñez, Pérez-Bilbao, \& Felipe, in press).

Professional padel players were also analyzed by evaluating the effectiveness at the net and its influence on match outcome regarding serve situation in professional padel players (Courel-Ibáñez, Sánchez-Alcaraz, \& Cañas, 2015). In particular, it was highlighted how the net game crucially influences professional padel successful because winning players made $49 \%$ less unforced errors at the net than those who lost, especially when resting. More recently, professional padel match was focused on the rally length considering attack effectiveness, players' location, and game outcome (Courel-Ibáñez, Sánchez-Alcaraz Martínez, \& Cañas, 2017), showing that: $40 \%$ of unforced errors were committed within the first four s of the rally, over $50 \%$ of points were scored between the $5^{\text {th }}$ and $11^{\text {th }} \mathrm{s}$, and $30 \%$ of forced errors occurred after the $11^{\text {th }} \mathrm{s}$ of the rally. Therefore, this highlighted the ability to score in rallies of over $11 \mathrm{~s}$ duration and to avoid errors within the first four $\mathrm{s}$ as the keys of success in professional padel matches.

Although these extremely recent information could promote useful references for coaches, further studies are warrant to confirm or identify the key aspects of this emerging racket sport, and to strengthen valuable references for training plans specifically tailored on gender and match outcome category. In addition, considering that technical and tactical results could be influenced by players' fatigue, data collections in relation to couple of games (i.e., the two games usually performed between two rest intervals before the court exchanges) could provide more objective information about padel performance. Therefore, this study aimed to analyze professional padel matches (i.e., World Padel Tour 2016) by means of technical and tactical indicators, hypothesizing differences between: i) women and men; and ii) winning and losing performances.

\section{Methods}

\section{Subjects}

The local Institutional Review Board approved this study to investigate the technical and tactical aspects of professional padel matches. For this purpose, the video recordings of 22 (women, $\mathrm{n}=10$; men, $\mathrm{n}=12$ ) entire official matches performed by 23 (women, $\mathrm{N}=9$; men, $\mathrm{n}=14$ ) different professional couples of padel players competing into the World Padel Tour 2016 (i.e., women tournaments: Abanca, Keler, Palma de Mallorca, Sevilla, Zaragoza; men tournaments: Abanca, Gran Canaria, La Nucia, Las Rozas, Palma de Mallorca, Sevilla, Zaragoza) have been analyzed. In particular, the professional padel matches of this sample consisted of 55 sets (women: 25, 2.5 \pm 0.5 ; men: 30, 2.5 \pm 0.5 ) and 231 couple of games

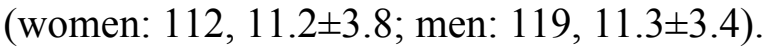

\section{Procedures}

The 22 professional padel matches were edited by means of the official youtube channel dedicated to the World Padel Tour broadcast (https://www.youtube.com/user/WorldPadelTourAJPP). A notational analysis was performed on all matches by means of 18 indicators (Table 1). 
Lupo, C.; Condello, G.; Courel-Ibañez, J.; Gallo, C.; Conte, D., \& Tessitore, A. (2018). Effect of gender and match outcome on professional padel competition. RICYDE. Revista internacional de ciencias del deporte, 51(14), 29-41. https://doi.org/10.5232/ricyde2018.05103

Table 1. Technical and tactical indicators used to analyze the professional padel performance.

\# $\quad$ General indicators

1. Wining rallies - mean occurrence of winning rallies within a couple of games;

2. Duration of rest intervals - mean duration of actual rest intervals between couples of games, before the half court players' exchange;

3. Duration of rallies - mean duration of active game for each rally;

4. Occurrence of strokes - mean occurrence of strokes within each rally;

5. Ace - mean occurrence of aces (i.e., serving where the ball lands inside the opponent's service court zone and is not touched by the receiver) in single couples of games;

6. First service fault - mean occurrence of first service fault (i.e., serving where the ball does not land inside the opponent's service court zone) in single couples of games;

7. Deuce - mean occurrence of deuce score (i.e., score of 40-40 in a game, where a player must win two consecutive rallies from a deuce to win the game) in single couples of games;

8. Smash determining ball out - mean occurrence of smashes (i.e., stroke that is hit above the hitter's head), which determine the exit of ball from the court and a winning point, in single couples of games.

Stroke technical indicators (i.e., percentage occurrence of specific type shots determining a winning point over the total winning strokes performed during a couple of games)

9. Forehand stroke;

10. Backhand stroke;

11. Forehand stroke with wall - forehand stroke after the ball bounce on one of the three walls;

12. Backhand stroke with wall - backhand stroke after the ball bounce on one of the three walls;

13. Forehand volley - forehand stroke where the tennis player strikes the ball before it bounces;

14. Backhand volley - backhand stroke where the tennis player strikes the ball before it bounces;

15. Smash.

Origin zone of the stroke (i.e., percentage occurrence of the strokes determining a winning point in relation to a determine court zone covered by the hitter over the total winning strokes performed during a couple of games);

16. Stroke close to net - stroke performed within the area delimited by the net and the trajectory between the two conjunction points between the two main metallic panels along the lateral walls (4 $\mathrm{m}$ from net according to Muñoz, Courel-Ibáñez, Sánchez-Alcaraz, Díaz, Grijota, \& Muñoz, 2017);

17. Stroke from midfield zone - stroke performed within the area delimited by the trajectory between the two conjunction points between the two main metallic panels along the lateral walls (Muñoz et al., 2017) and the service line;

18. Stroke from baseline zone - stroke performed within the area delimitated between the service line and the court back wall.

To avoid inter-observer variability, a single observer (more than two years of specific experience in analyzing padel matches) scored all matches. However, to assess reliability, the observer who completed this study analyzed a randomly chosen match twice, each observation separated by 14 days, reporting a high intra-observer test-retest reliability (Intraclass Correlations, ICC $=0.99$ ). In addition, another randomly chosen match was recorded by a second independent observer (more than two years of experience) to compare this records with the main observer and assess the inter-observer reliability (ICC range $=$ $0.98)$. 
Lupo, C.; Condello, G.; Courel-Ibañez, J.; Gallo, C.; Conte, D., \& Tessitore, A. (2018). Effect of gender and match outcome on professional padel competition. RICYDE. Revista internacional de ciencias del deporte, 51(14), 29-41. https://doi.org/10.5232/ricyde2018.05103

\section{Data analysis}

Mean data of couple of padel games were calculated for each couple of players to apply the statistical analyses in relation to gender and match outcome variables. Actually, for a complete analysis of the matches, also the data referring to beginning game and the eventual last game of the match was included in the experimental data (excepting for the indicator "winning rallies", which was expressed in absolute terms instead of mean or percentage values).

For each of the 18 performance indicators, means and standard deviations $(\mathrm{M} \pm \mathrm{SD})$ were calculated in relation to gender and match outcome subgroups. The Shapiro-Wilk test was considered to verify data normal distribution. Considering that not all the dependent variables were normally distributed, a non-parametric approach (Mann-Whitney U test) was applied to evaluate differences in terms of gender (i.e., male performance versus female performance), and match outcome (i.e., winning versus losing couple of players), and their interactions (i.e., male winning versus male losing performance; female winning versus female losing performance). Finally, for the differences evaluated by means a non-parametric approach, the phi ESs were applied, considering $0.1,0.3$, and 0.5 as small, medium, and large ESs, respectively (Huck, 2000). Statistical analyses were conducted using SPSS (version 21.0; Armonk, NY: IBM Corp.) and the criterion for significance was set at $\mathrm{P} \leq 0.05$.

\section{Results}

Descriptive statistics $(\mathrm{M} \pm \mathrm{SD})$, and the related effects (P value) and ESs of the 18 indicators were reported in relation to gender (Table 2), match outcome regardless of gender (Table 3), and match outcome only for women (Table 4) and men (Table 5) performances.

For the analysis of padel competition in relation to gender, professional female players reported a higher duration and occurrence of rallies, occurrence of first service faults, and frequency (\%) of backhand strokes, and strokes from midfield area with respect to the gender counterparts. Conversely, the opposite picture emerged for the occurrence of smashes determining ball out, and the frequency of backhand strokes with volley, and strokes close to net (Table 2).

Table 2. Means and standard deviations $(\mathrm{M} \pm \mathrm{SD})$, significance $(\mathrm{P} \leq 0.05)$, effect size (ES) of technical and tactical indicators in relation to women's and men's performance.

\begin{tabular}{|c|c|c|c|c|c|}
\hline \# Indicator & Type of indicator & Women & Men & P value & ES \\
\hline & General indicators & & & & \\
\hline 1 & Winning rallies $(n)$ & $5.7 \pm 1.0$ & $5.4 \pm 0.9$ & 0.377 & \\
\hline 2 & Duration of rest intervals (s) & $30.4 \pm 5.7$ & $28.8 \pm 6.9$ & 0.322 & \\
\hline 3 & Duration of rallies (s) & $16.8 \pm 2.8$ & $12.6 \pm 2.1$ & $<0.001$ & $0.6-$ large \\
\hline 4 & Occurrence of strokes $(n)$ & $12.2 \pm 2.0$ & $9.6 \pm 1.5$ & $<0.001$ & $0.7-$ large \\
\hline 5 & $\operatorname{Ace}(n)$ & $0.2 \pm 0.1$ & $0.2 \pm 0.1$ & 0.603 & \\
\hline 6 & First service fault $(n)$ & $0.9 \pm 0.3$ & $0.5 \pm 0.3$ & $<0.001$ & $0.6-$ large \\
\hline 7 & Deuce $(n)$ & $0.4 \pm 0.2$ & $0.4 \pm 0.2$ & 0.310 & \\
\hline \multirow[t]{2}{*}{8} & Smash determining ball out $(n)$ & $0.2 \pm 0.2$ & $0.4 \pm 0.2$ & $<0.001$ & 0.5 - large \\
\hline & Stroke technical indicators & & & & \\
\hline 9 & Forehand stroke $(\%)$ & $11.4 \pm 4.4$ & $10.9 \pm 4.9$ & 0.621 & \\
\hline 10 & Backhand stroke (\%) & $7.8 \pm 3.6$ & $6.1 \pm 4.1$ & 0.02 & $0.4-$ medium \\
\hline
\end{tabular}


Lupo, C.; Condello, G.; Courel-Ibañez, J.; Gallo, C.; Conte, D., \& Tessitore, A. (2018). Effect of gender and match outcome on professional padel competition. RICYDE. Revista internacional de ciencias del deporte, 51(14), 29-41. https://doi.org/10.5232/ricyde2018.05103

\begin{tabular}{|c|c|c|c|c|c|}
\hline 11 & Forehand stroke with wall (\%) & $11.0 \pm 5.7$ & $10.1 \pm 4.7$ & 0.724 & \\
\hline 12 & Backhand stroke with wall (\%) & $8.0 \pm 6.4$ & $5.7 \pm 5.2$ & 0.064 & \\
\hline 13 & Forehand volley $(\%)$ & $15.5 \pm 6.0$ & $15.1 \pm 6.8$ & 0.759 & \\
\hline 14 & Backhand volley (\%) & $12.5 \pm 6.7$ & $16.4 \pm 4.5$ & 0.027 & $0.3-$ medium \\
\hline \multirow[t]{2}{*}{15} & Smash $(\%)$ & $33.9 \pm 11.1$ & $35.7 \pm 8.8$ & 0.654 & \\
\hline & Origin zone of the stroke & & & & \\
\hline 16 & Stroke close to net $(\%)$ & $20.9 \pm 8.9$ & $34.2 \pm 11.9$ & 0.001 & $0.5-$ large \\
\hline 17 & Stroke from midfield zone $(\%)$ & $51.6 \pm 12.5$ & $42.9 \pm 9.4$ & 0.012 & $0.4-$ medium \\
\hline 18 & Stroke from baseline zone $(\%)$ & $27.5 \pm 9.1$ & $23.0 \pm 8.3$ & 0.144 & \\
\hline
\end{tabular}

In terms of match outcome, the present data reported a difference only for the occurrence of winning rallies for the analysis regardless the gender discrimination (Table 3), as well as for that related to the women (Table 4) and men (Table 5) performances.

Table 3. Means and standard deviations $(\mathrm{M} \pm \mathrm{SD})$, significance $(\mathrm{P} \leq 0.05)$, effect size (ES) of technical and tactical indicators in relation to winning and losing performance.

\begin{tabular}{|c|c|c|c|c|c|}
\hline \# Indicator & Type of indicator & Winning & Losing & P value & ES \\
\hline & General indicators & & & & \\
\hline 1 & Winning rallies $(n)$ & $6.1 \pm 0.7$ & $5.0 \pm 0.8$ & $<0.001$ & $0.6-$ large \\
\hline 2 & Duration of rest intervals (s) & $30.2 \pm 6.2$ & $28.8 \pm 6.7$ & 0.439 & \\
\hline 3 & Duration of rallies (s) & $14.2 \pm 3.2$ & $14.8 \pm 3.2$ & 0.647 & \\
\hline 4 & Occurrence of strokes $(n)$ & $10.6 \pm 2.1$ & $11.0 \pm 2.2$ & 0.511 & \\
\hline 5 & $\operatorname{Ace}(n)$ & $0.2 \pm 0.1$ & $0.2 \pm 0.2$ & 0.934 & \\
\hline 6 & First service fault $(n)$ & $0.7 \pm 0.3$ & $0.6 \pm 0.4$ & 0.245 & \\
\hline 7 & Deuce $(n)$ & $0.4 \pm 0.2$ & $0.4 \pm 0.2$ & 0.372 & \\
\hline \multirow[t]{2}{*}{8} & Smash determining ball out $(n)$ & $0.4 \pm 0.2$ & $0.3 \pm 0.2$ & 0.121 & \\
\hline & Stroke technical indicators & & & & \\
\hline 9 & Forehand stroke $(\%)$ & $11.3 \pm 3.7$ & $10.9 \pm 5.4$ & 0.742 & \\
\hline 10 & Backhand stroke (\%) & $6.4 \pm 2.6$ & $7.3 \pm 5.0$ & 0.833 & \\
\hline 11 & Forehand stroke with wall (\%) & $10.1 \pm 3.8$ & $10.9 \pm 6.2$ & 0.888 & \\
\hline 12 & Backhand stroke with wall (\%) & $5.7 \pm 3.0$ & $7.8 \pm 7.6$ & 0.622 & \\
\hline 13 & Forehand volley (\%) & $15.3 \pm 5.7$ & $15.3 \pm 7.1$ & 0.925 & \\
\hline 14 & Backhand volley (\%) & $14.6 \pm 5.5$ & $14.7 \pm 6.4$ & 0.907 & \\
\hline \multirow[t]{2}{*}{15} & Smash $(\%)$ & $36.6 \pm 7.4$ & $33.1 \pm 11.7$ & 0.336 & \\
\hline & Origin zone of the stroke & & & & \\
\hline 16 & Stroke close to net $(\%)$ & $28.8 \pm 11.3$ & $27.5 \pm 13.7$ & 0.606 & \\
\hline 17 & Stroke from midfield zone $(\%)$ & $48.2 \pm 11.9$ & $45.4 \pm 11.4$ & 0.467 & \\
\hline 18 & Stroke from baseline zone $(\%)$ & $23.0 \pm 7.3$ & $27.0 \pm 10.0$ & 0.121 & \\
\hline
\end{tabular}


Lupo, C.; Condello, G.; Courel-Ibañez, J.; Gallo, C.; Conte, D., \& Tessitore, A. (2018). Effect of gender and match outcome on professional padel competition. RICYDE. Revista internacional de ciencias del deporte, 51(14), 29-41. https://doi.org/10.5232/ricyde2018.05103

Table 4. Means and standard deviations $(M \pm S D)$, significance $(P \leq 0.05)$, effect size (ES) of technical and tactical indicators in relation to women's winning and losing performance.

\begin{tabular}{|c|c|c|c|c|c|}
\hline \# Indicator & Type of indicator & Winning & Losing & $P$ value & ES \\
\hline & General indicators & & & & \\
\hline 1 & Winning rallies $(n)$ & $6.3 \pm 0.5$ & $5.1 \pm 1.0$ & 0.009 & $0.6-$ large \\
\hline 2 & Duration of rest intervals (s) & $30.6 \pm 6.4$ & $30.1 \pm 5.4$ & 0.912 & \\
\hline 3 & Duration of rallies (s) & $17.0 \pm 2.9$ & $17.0 \pm 2.9$ & 0.853 & \\
\hline 4 & Occurrence of strokes $(n)$ & $12.1 \pm 2.0$ & $12.3 \pm 2.1$ & 0.912 & \\
\hline 5 & $\operatorname{Ace}(n)$ & $0.2 \pm 0.1$ & $0.2 \pm 0.2$ & 0.912 & \\
\hline 6 & First service fault $(n)$ & $1.0 \pm 0.3$ & $0.8 \pm 0.3$ & 0.28 & \\
\hline 7 & Deuce $(n)$ & $0.4 \pm 0.3$ & $0.4 \pm 0.2$ & 0.529 & \\
\hline \multirow[t]{2}{*}{8} & Smash determining ball out $(n)$ & $0.3 \pm 0.2$ & $0.2 \pm 0.1$ & 0.393 & \\
\hline & Stroke technical indicators & & & & \\
\hline 9 & Forehand stroke (\%) & $11.3 \pm 3.4$ & $11.5 \pm 5.3$ & 0.971 & \\
\hline 10 & Backhand stroke (\%) & $7.2 \pm 2.6$ & $8.4 \pm 4.5$ & 0.631 & \\
\hline 11 & Forehand stroke with wall (\%) & $10.2 \pm 3.8$ & $11.7 \pm 7.3$ & 0.739 & \\
\hline 12 & Backhand stroke with wall (\%) & $6.9 \pm 2.5$ & $9.1 \pm 8.8$ & 0.598 & \\
\hline 13 & Forehand volley (\%) & $15.0 \pm 6.3$ & $16.0 \pm 6.1$ & 0.684 & \\
\hline 14 & Backhand volley (\%) & $12.2 \pm 5.9$ & $12.8 \pm 7.8$ & 0.971 & \\
\hline \multirow[t]{2}{*}{15} & Smash $(\%)$ & $37.3 \pm 9.2$ & $30.5 \pm 12.1$ & 0.247 & \\
\hline & Origin zone of the stroke & & & & \\
\hline 16 & Stroke close to net $(\%)$ & $21.9 \pm 7.9$ & $19.9 \pm 10.1$ & 0.631 & \\
\hline 17 & Stroke from midfield zone $(\%)$ & $54.0 \pm 12.8$ & $49.1 \pm 12.3$ & 0.353 & \\
\hline 18 & Stroke from baseline zone $(\%)$ & $24.0 \pm 8.3$ & $31.0 \pm 9.3$ & 0.075 & \\
\hline
\end{tabular}

Table 5. Means and standard deviations $(\mathrm{M} \pm \mathrm{SD})$, significance $(\mathrm{P} \leq 0.05)$, effect size (ES) of technical and tactical indicators in relation to men's winning and losing performance.

\begin{tabular}{|c|c|c|c|c|c|}
\hline \# Indicator & Type of indicator & Winning & Losing & P value & ES \\
\hline & General indicators & & & & \\
\hline 1 & Winning rallies $(n)$ & $6.0 \pm 0.8$ & $4.9 \pm 0.7$ & 0.001 & $0.5-$ large \\
\hline 2 & Duration of rest intervals (s) & $29.9 \pm 6.2$ & $27.7 \pm 7.6$ & 0.378 & \\
\hline 3 & Duration of rallies (s) & $12.1 \pm 1.7$ & $13.2 \pm 2.4$ & 0.514 & \\
\hline 4 & Occurrence of strokes $(n)$ & $9.3 \pm 1.3$ & $9.9 \pm 1.8$ & 0.347 & \\
\hline 5 & $\operatorname{Ace}(n)$ & $0.2 \pm 0.2$ & $0.2 \pm 0.1$ & 0.977 & \\
\hline 6 & First service fault $(n)$ & $0.5 \pm 0.3$ & $0.5 \pm 0.3$ & 0.514 & \\
\hline 7 & Deuce $(n)$ & $0.3 \pm 0.2$ & $0.4 \pm 0.3$ & 0.443 & \\
\hline \multirow[t]{2}{*}{8} & Smash determining ball out $(n)$ & $0.5 \pm 0.2$ & $0.4 \pm 0.2$ & 0.266 & \\
\hline & Stroke technical indicators & & & & \\
\hline 9 & Forehand stroke (\%) & $11.3 \pm 4.0$ & $10.4 \pm 5.7$ & 0.478 & \\
\hline
\end{tabular}


Lupo, C.; Condello, G.; Courel-Ibañez, J.; Gallo, C.; Conte, D., \& Tessitore, A. (2018). Effect of gender and match outcome on professional padel competition. RICYDE. Revista internacional de ciencias del deporte, 51(14), 29-41. https://doi.org/10.5232/ricyde2018.05103

\begin{tabular}{llrrr}
10 & Backhand stroke (\%) & $5.8 \pm 2.6$ & $6.3 \pm 5.3$ & 0.514 \\
11 & Forehand stroke with wall (\%) & $10.0 \pm 4.0$ & $10.2 \pm 5.4$ & 0.977 \\
12 & Backhand stroke with wall (\%) & $4.6 \pm 3.1$ & $6.8 \pm 6.7$ & 0.671 \\
13 & Forehand volley (\%) & $15.5 \pm 5.5$ & $14.8 \pm 8.1$ & 0.799 \\
14 & Backhand volley (\%) & $16.7 \pm 4.4$ & $16.2 \pm 4.9$ & 0.887 \\
15 & Smash (\%) & $36.1 \pm 5.9$ & $35.2 \pm 11.3$ & 0.755 \\
& Origin zone of the stroke & & & \\
16 & Stroke close to net (\%) & $34.5 \pm 10.7$ & $33.9 \pm 13.4$ & 0.755 \\
17 & Stroke from midfield zone (\%) & $43.4 \pm 8.9$ & $42.4 \pm 10.1$ & 0.887 \\
18 & Stroke from baseline zone (\%) & $22.1 \pm 6.5$ & $23.8 \pm 10.0$ & 0.63 \\
\hline
\end{tabular}

\section{Discussion}

The present study aimed to analyze the technical and tactical aspects of professional padel, evaluating potential performance differences in terms of gender and match outcome. Findings show that substantial differences exist between the women and men performances, whereas no particular technical and tactical aspect seems to discriminate the winning and losing performance, speculating that match successful could be achieved by means of different playing styles.

Differences between men and women technical and tactical performances found valuable references from the results of previous studies on professional padel (Sánchez-Alcaraz, 2014b; Torres-Luque et al., 2015). Overall, in terms of absolute values, the mean duration of rallies recorded in this study resulted in line with the results of Sánchez-Alcaraz (2014b) for both genders of players, whereas shorter durations were reported in the study of TorresLuque et al. (2015), in which no difference emerged between genders and the mean duration of a rally resulted lower than $10 \mathrm{~s}$. In addition, controversial results emerged by the analysis of Courel-Ibáñez et al. (2017), who highlight that $80 \%$ of rallies in professional padel matches were solved within the first $11 \mathrm{~s}$. However, for the comparison of performances related to the gender of players, coherently to Sánchez-Alcaraz (2014b), the mean duration of rallies registered during the World Padel Tour 2016 matches resulted strongly longer in women than in men competition (also considering the large ES), despite no effect was reported for the mean duration of rest intervals between rallies.

The percentage distribution of the stroke technical type performed for winning points showed as smash was the most effective technique in both genders with around one third of the total winning strokes. This result is confirmed by a previous analysis on similar padel competition level (Torres-Luque et al., 2015), where the $17 \%$ of all total strokes included a smash (i.e., smash or indirect smash). This prevalence of over-head strokes could be also determined by the execution of antecedent previous wrong lobs (i.e., shorter with respect to the opponent playing position), which could have been performed due to the need of defending against the opponents' attacking close to net by sending the back to the baseline (Muñoz et al., 2017).

In regards to gender differences, women made more backhand strokes whilst men made more backhand volleys (medium ES). Although the same picture did not emerged for forehand strokes and volleys, this higher frequency of backhand strokes could be associated to the prevalence of strokes performed from midfield zone (mainly back- and forehand strokes) and 
Lupo, C.; Condello, G.; Courel-Ibañez, J.; Gallo, C.; Conte, D., \& Tessitore, A. (2018). Effect of gender and match outcome on professional padel competition. RICYDE. Revista internacional de ciencias del deporte, 51(14), 29-41. https://doi.org/10.5232/ricyde2018.05103

close to net (mainly volleys). In padel, volleys get a relevant importance as accounted for the $30 \%$ of the total strokes in a game (Torres-Luque et al., 2015); plus, the vast majority of points scored $(80 \%)$ came from the net area (Courel-Ibáñez et al., 2015). Hence, these differences in the use of volleys between men and female could be related to particular offensive strategies to enhance scoring options by applying spin to vary the depth, angle, height, speed, and bounce of the shot like in tennis (United States Tennis Association, 2004).

Even though no gender effect emerged for aces, the higher occurrence of the first service faults reported by women with respect to men could be interpreted in favour of a higher predisposition to obtain an ace by forcing the first service. In particular, it could be speculated that women try more frequently to serve the ball close to the lateral wall inside the service box in order to determine an uncomfortable opponent's stroke response, favouring the touch of the ball on the wall before the court, which determines the first service fault. TorresLuque et al. (2015) showed that the second service (performed following the first service fault) is rarely performed (i.e., $1.55 \%$ of all performed strokes) with respect to the first one (i.e., $9.56 \%$ of all performed strokes) in professional padel matches. However, it is important noting that "serve and volley" strategy in padel (Courel-Ibáñez et al., 2015; Muñoz et al., 2017) could be assumed as the main aim when serving instead of an ace (i.e., after the serve, players approach to the net from where the most of the points are scored, and take advantage of possible opponents' errors like a short lob). There is therefore a need of clarifications about effective service strategies in padel by means of further research.

Important differences in technical and tactical performances were observed between men and women professional padel players. Therefore, two separated game profiles, which could be determined by different behaviours or coaching modalities, have been highlighted (Chalabaev, Sarrazin, Fontayne, Boiché, \& Clément-Guillotin, 2013). For instance, men scored more points through smashes determining ball out with respect to women, speculating that this game strategy could be more adopted by male than female padel players probably because of a different grade of strength or a better over-headed strokes specific training. This is important considering the great incidence of upper body injuries in padel (Castillo-Lozano \& Casuso-Holgado, 2016). However, the effect of injury prevention and physical conditioning interventions in padel is a question than need to be scientifically addressed, also in relation to gender.

As expected, the mean occurrence of winning rallies resulted strongly (i.e., large ES) higher in winning padel performance with respect to the losing one, however no other effect was reported for this factor (i.e., match outcome in general, women, and men performance). This may arise two main interpretations: first, that match outcome is mainly determined by different playing styles; second, that padel game presents a solid structure, in where the stroke type is strongly determined by players' spatial location and defined by particular patterns (e.g., baseline stroke plus net volley, baseline lob plus smash) according to offensive (winning the net area) and defensive (recover the net and send the opponent back to the baseline) aims (Muñoz et al., 2017).

Although this is the first study addressing technical tactical differences in relation to gender in elite padel, the study presents some limitations. In particular, the main limitations are referred to the situational nature of padel performance and the limited number of analyzed games. Therefore, future research should likely replicate this study with a larger sample size and further investigate the parameters differentiating between winning and losing teams in both men and women padel games. Moreover, further studies should also include other technical and tactical aspects such as different match phases (Gómez, DelaSerna, Lupo, \& 
Lupo, C.; Condello, G.; Courel-Ibañez, J.; Gallo, C.; Conte, D., \& Tessitore, A. (2018). Effect of gender and match outcome on professional padel competition. RICYDE. Revista internacional de ciencias del deporte, 51(14), 29-41. https://doi.org/10.5232/ricyde2018.05103

Sampaio, 2014), game locations (Gómez, DelaSerna, Lupo, \& Sampaio, 2016), or margins of victory (Lupo \& Tessitore, 2016). More specifically, padel game dynamics and match outcome could be exclusively analyzed for the final period of close (i.e., balance score) matches (Gomez, Gasperi, \& Lupo, 2016). In addition, further studies on the analysis of physical performances (i.e., countermovement jump and handgrip) before and after official matches (Chiodo, Tessitore, Cortis, Lupo Ammendolia, \& Capranica, 2012), time motion analysis (Conte, Favero, Lupo, Francioni, Capranica, \& Tessitore, 2015) and game-based conditioning tests (Conte, Tessitore, Smiley, Thomas, \& Favero (2016), physiological and psychological aspects (Casolino, Cortis, Lupo, Chiodo, Minganti, \& Capranica, 2012), or integrated analyses which simultaneously consider heart rate, motion, and technical and tactical aspects (Lupo, Capranica, Cugliari, Gómez, \& Tessitore, 2016), could substantially improve the knowledge of this emerging sport.

\section{Conclusions}

Although the nature of situational sports regularly affects the replication of game analyses (Lupo, Minganti, Cortis, Perroni, Capranica, \& Tessitore, 2012), and the present findings have been discussed by referring to few and recent studies on technical and tactical aspects of professional padel (Courel-Ibáñez et al., 2015, 2017; Sánchez-Alcaraz, 2014b; Torres-Luque et al., 2015), this study represents a valuable contribute for increasing the knowledge of situational sports and for better coaching (Hughes \& Franks, 2004).

The evident divergences emerged between women and men performance could effectively contribute to improve the quality of training plans. In particular, women training sessions should include longer duration rallies (performing a substantial occurrence of consecutive strokes), limit the first service faults, and maintain a good effectiveness of the backhand strokes especially from midfield zone. On the other hand, men training plans should mainly consider smashes determining ball out and backhand volley strokes performed close to net. In addition, despite no particular technical and tactical aspects have been highlighted in terms of match victory, successful training could be planned considering those game situations that more often determined the scoring of points, such as smashes and strokes performed from midfield zone.

Finally, although the current study has been focused on technical and tactical aspects of padel, useful contributions on physical aspects of this sport could be also provided. In this sense, professional padel coaches could propose physical training sessions supporting the development of strength and effective moving within padel court to improve the effectiveness of smashes, which highly characterizes the professional padel performance, especially to solve the point (determining ball out) in men performance.

\section{References}

Akpinar, S.; Devrilmez, E., \& Kirazci, S. (2012). Coincidence-anticipation timing requirements are different in racket sports. Perceptual and Motor Skills, 115(2), 581593.

https://doi.org/10.2466/30.25.27.PMS.115.5.581-593

Cabello Manrique, D., \& González-Badillo, J. J. (2003). Analysis of the characteristics of competitive badminton. British Journal of Sports Medicine, 37(1), 62-66. https://doi.org/10.1136/bjsm.37.1.62

Carrasco, L.; Romero, S., Sañudo, B., \& de Hoyo, M. (2011). Game analysis and energy requirements of padel competition. Science \& Sports, 26(6), 338-344.

https://doi.org/10.1016/j.scispo.2010.12.016 
Lupo, C.; Condello, G.; Courel-Ibañez, J.; Gallo, C.; Conte, D., \& Tessitore, A. (2018). Effect of gender and match outcome on professional padel competition. RICYDE. Revista internacional de ciencias del deporte, 51(14), 29-41. https://doi.org/10.5232/ricyde2018.05103

Casolino, E.; Cortis C., Lupo, C., Chiodo, S., Minganti, C., \& Capranica, L. (2012). Physiological vs Psychological Evaluation in Taekwondo Elite Athletes. International Journal of Sports Physiology and Performance, 7(4), 322-331.

https://doi.org/10.1123/ijspp.7.4.322

Chalabaev, A., Sarrazin, P., Fontayne, P., Boiché, J., \& Clément-Guillotin, C. (2013). The influence of sex stereotypes and gender roles on participation and performance in sport and exercise: Review and future directions. Psychology of Sport and Exercise, 14(2), 136-144.

https://doi.org/10.1016/j.psychsport.2012.10.005

Chin, M. K.; Steininger, K., So, R. C., Clark, C. R., \& Wong, A. S. (1995). Physiological profiles and sport specific fitness of Asian elite squash players. British Journal of Sports Medicine, 29(3), 158-164.

https://doi.org/10.1136/bjsm.29.3.158

Chiodo, S.; Tessitore, A., Cortis, C., Lupo, C., Ammendolia, A., \& Capranica, L. (2012). Effects of Official Youth Taekwondo Competitions on Jump and Strength Performances. European Journal of Sport Science, 12(2), 113-120. https://doi.org/10.1080/17461391.2010.545837

Conte, D.; Favero, T. G., Lupo, C., Francioni, F. M., Capranica, L., \& Tessitore, A. (2015). Time-motion analysis of Italian elite women basketball games: individual and team analyses. Journal of Strength and Conditioning Research, 29(1), 144-150. https://doi.org/10.1519/JSC.0000000000000633

Conte, D.; Tessitore, A., Smiley, K., Thomas, C., \& Favero, T. G. (2016). Performance profile of NCAA division I men's basketball games and training sessions. Biology of Sport, 33(2), 189-194.

https://doi.org/10.5604/20831862.1200512

Courel-Ibáñez, J.; Sánchez-Alcaraz, B. J, Benítez, S., \& Echegaray, M. (2017). Evolution of padel in Spain according to practitioners' gender and age. Cultura, Ciencia $y$ Deporte, 12(34), 39-46.

Courel-Ibáñez, J.; Sánchez-Alcaraz, B. J., \& Cañas, J. (2015). Effectiveness at the net as a predictor of final match outcome in professional padel players. International Journal of Performance Analysis in Sport, 15(2), 632-640.

Courel-Ibáñez, J.; Sánchez-Alcaraz Martínez, B. J., \& Cañas, J. (2017). Game performance and length of rally in professional padel players. Journal of Human Kinetics, 55, 161-169.

Ferrauti, A.; Bergeron, M. F., Pluim, B. M., \& Weber, K. (2001). Physiological responses in tennis and running with similar oxygen uptake. European Journal of Applied Physiology, 85, 27-33.

https://doi.org/10.1007/s004210100425

Faude, O.; Meyer, T., Rosenberger, F., Fries, M., Huber, G., \& Kindermann, W. (2007). Physiological characteristics of badminton match play. European Journal of Applied Physiology, 100(4), 479-485.

https://doi.org/10.1007/s00421-007-0441-8

García-Benítez, S.; Courel-Ibáñez, J., Pérez-Bilbao, T., \& Felipe, J. L. (in press). Game responses during young padel match play: age and gender comparisons. Journal of Strength and Conditioning Research. $x(x \mathrm{x}), \mathrm{x}-\mathrm{x}$

Girard, O.; Chevalier, R., Habrard, M., Sciberras, P., Hot, P., \& Millet, G. P. (2007). Game analysis and energy requirements of elite squash. Journal of Strength and Conditioning Research, 21(3), 909-914.

https://doi.org/10.1519/R-20306.1 
Lupo, C.; Condello, G.; Courel-Ibañez, J.; Gallo, C.; Conte, D., \& Tessitore, A. (2018). Effect of gender and match outcome on professional padel competition. RICYDE. Revista internacional de ciencias del deporte, 51(14), 29-41. https://doi.org/10.5232/ricyde2018.05103

Gómez-Ruano, M. A. (2017). The importance of performance analysis as an emergent research topic in sport sciences. RICYDE. Revista Internacional de Ciencias del Deporte, 47(13), 1-4.

https://doi.org/10.5232/ricyde2017.047ed

Gómez, M. A.; DelaSerna, A., Lupo, C., \& Sampaio, J. (2014). Effects of Situational Variables and Starting Quarter Score in the outcome of elite women water polo game quarters. International Journal of Performance Analysis in Sport, 14(1), 73-83.

Gómez, M. A.; DelaSerna, A., Lupo, C., \& Sampaio, J. (2016). Effects of Game Location, Quality of Opposition and Starting Quarter Score in the outcome of elite water polo quarters. Journal of Strength and Conditioning Research, 30(4), 1014-1020. https://doi.org/10.1519/JSC.0b013e3182aa5f59

Gómez M. A.; Gasperi L., \& Lupo C. (2016). Performance analysis of game dynamics during the 4th game quarter of NBA close games. International Journal of Performance Analysis in Sport, 16(1), 249-263.

Hopkins, W. G. (2016). A scale of magnitudes for effect statistics. Retrieved from http://www.sportsci.org/resource/stats/effectmag.html. Accessed October 3, 2016.

Huck, S. W. (2000). Reading statistics and research (3rd ed). (pp.628-629). New York, NY: Addition, Wesly Longman.

Hughes, M., \& Franks, I. (2004). From analysis to coaching. In M. Hughes \& I. Franks (Eds.), Notational analysis of sport: Systems for better coaching and performance in sport (pp.257-271). London: Routledge.

Lees, A. (2003). Science and the major racket sports: a review. Journal of Sports Sciences, 21(9), 707-732. https://doi.org/10.1080/0264041031000140275

Lupo, C.; Minganti, C., Cortis, C., Perroni, F., Capranica, L., \& Tessitore, A. (2012). Effects of competition level on the centre forward role of men water polo. Journal of Sports Sciences, 30(9), 889-897.

https://doi.org/10.1080/02640414.2012.679673

Lupo, C., \& Tessitore, A. (2016). How important is the final outcome to interpret match analysis data: the influence of scoring a goal, and difference between close and balance games in elite soccer. Comment on Lago-Peñas and Gómez-López. Perceptual \& Motor Skills, 122(1), 280-285. https://doi.org/10.1177/0031512515626629

Lupo, C.; Capranica, L., Cugliari, G., Gómez, M. A., \& Tessitore, A. (2016). Tactical, swimming activity, and heart rate aspects of youth water polo game. Journal of Sports Medicine and Physical Fitness, 56(9), 997-1006.

Muñoz, D.; Courel-Ibáñez, J., Sánchez-Alcaraz, B. J., Díaz, J., Grijota, F., \& Muñoz, J. (2017). Analysis of the use and effectiveness of lobs to recover the net regarding game context in padel. Retos, 31, 19-22.

O'Donoghue, P., \& Ingram, B. (2001). A notational analysis of elite tennis strategy. Journal of Sports Sciences, 19(2), 107-115. https://doi.org/10.1080/026404101300036299

Ooi, C. H.; Tan, A., Ahmad, A., Kwong, K. W., Sompong, R., Ghazali, K. A. M., \& Thompson, M. W. (2009). Physiological characteristics of elite and sub-elite badminton players. Journal of Sports Sciences, 27(14), 1591-1599.

https://doi.org/10.1080/02640410903352907 
Lupo, C.; Condello, G.; Courel-Ibañez, J.; Gallo, C.; Conte, D., \& Tessitore, A. (2018). Effect of gender and match outcome on professional padel competition. RICYDE. Revista internacional de ciencias del deporte, 51(14), 29-41. https://doi.org/10.5232/ricyde2018.05103

Sánchez-Alcaraz, B. J. (2014a). Análisis de la exigencia competitiva del pádel en jóvenes jugadores. Competitive analysis of requirement of young paddle players. Kronos, 13(1), 1-9.

Sánchez-Alcaraz, B. J. (2014b). Game actions and temporal structure differences between male and female professional paddle players. Acción Motriz, 12, 17-35.

Sánchez-Alcaraz, B. J.; Courel-Ibáñez, J., \& Cañas, J. (2016). Groundstroke accuracy assessment in padel players according to their level of play. RICYDE. Revista International de Ciencias del Deporte, 45(12), 324-333. https://doi.org/10.5232/ricyde2016.04507

Smekal, G.; von Duvillard, S. P., Rihacek, C., Pokan, R., Hofmann, P., Baron, R., \& Bachl, N. (2001). A physiological profile of tennis match play. Medicine and Science in Sports and Exercise, 33(6), 999-1005. https://doi.org/10.1097/00005768-200106000-00020

Torres-Luque, G.; Ramirez, A., Cabello-Manrique, D., Nikolaidis, P. T., \& Alvero-Cruz, J. R. (2015). Match analysis of elite players during paddle tennis competition. International Journal of Performance Analysis in Sport, 15(3), 1135-1144. https://doi.org/10.1080/24748668.2015.11868857

United States Tennis Association (2004). Coaching Tennis successfully (2nd ed). Champaign: Human Kinetics

Villena-Serrano, M.; Castro-López, R., Lara-Sánchez, A., \& Cachón-Zagalaz, J. (2016). A systematic review of the characteristic and impact of paddle tennis in Spain. Apunts. Educación física y deportes, 4(126), 7-22. 